\section{Twenty-first century genomics for sports medicine: what does it all mean?}

\author{
Nick Webborn, ${ }^{1}$ H Paul Dijkstra ${ }^{2}$
}

We can easily be left behind by the explosion in technological developments in medicine-or is it just a sign of getting older? Many of us will remember a time before MRI were readily available, and having to learn what fat suppressed images, T1s and T2s actually meant.

Genomics is another example of a rapidly expanding technological development with major implications for medicine, and even experienced clinicians (many without formal training in molecular biology) are struggling to understand this. It requires learning a whole new language. The sequencing of the 3.2 billion nucleotides that compose the human genome was first completed only in 2003, at an estimated cost of $\$ 2.7$ billion. At the time, it was simply something of interest, unlikely to influence our working lives any time soon. Now, in just over a decade, it is possible to sequence the whole genome for $\$ 1000$.

\section{GENOMICS LITERACY - WHAT DOES IT ALL MEAN?}

Genomics is finding its place in medicine, from genetic testing for rare disorders to personalised medicine based on our genetic make up (see page 1517). However, the role of most of the genes in the human genome is still unknown.

A 'snip' is no longer just a glib term for vasectomy, because in genomics, an SNP (pronounced 'snip') is a 'single nucleotide polymorphism'. SNPs are locations within the human genome where the type of nucleotide present can differ between individuals. You also need to know Genome-wide Association Studies (GWAS) from candidate gene study in the new world of 'Omics'. Candidate gene studies test the validity of an 'educated guess' of one or more variants within the candidate gene in relation to a particular condition, for example, Achilles

${ }^{1}$ Centre for Sport and Exercise Science and Medicine (SESAME), University of Brighton, Eastbourne, East Sussex, UK; ${ }^{2}$ Aspetar-Qatar Orthopaedic \& Sports Medicine Hospital, Doha, Qatar

Correspondence to Professor Nick Webborn, Centre for Sport and Exercise Science and Medicine (SESAME), University of Brighton, Carlisle Rd, Eastbourne, East Sussex BN20 7NS, UK; nickwebborn@sportswise.org.uk tendinopathy and the COL1A1 gene, which encodes for the $\alpha 1(\mathrm{I})$ chain of type I collagen (see page 1497). They were predominantly used before testing of the whole genome became easily available. GWAS examine SNPs across the genome, looking for associations with particular conditions. Scanning the whole genome is a broad fishing expedition approach without any prior assumptions.

'Omics' technologies (figure 1) are aimed at the universal detection of genes (genomics), messenger RNA (mRNA) (transcriptomics), proteins (proteomics) and metabolites (metabolomics), with the contention that a complex system can be more easily understood if considered as a whole. Claude Bouchard reflects on the complexity of exercise genomics and how little we really know. The research to date has failed to adequately deliver results, but Bouchard shares a clear alternative view for future research.

\section{THE 'SCIENCEPLOITATION' OF DIRECT-TO-CONSUMER GENETIC TESTING FOR TALENT ID}

We need to be able to critically review information-another important reason for sport and exercise medicine to get to grips with the new world of 'Omics'. Sequencing or genotyping is much cheaper now and therefore readily available, but the interpretation of results is still at an early stage. It is, in fact, open to what has been termed 'scienceploitation'.

Researchers can be blamed for overemphasising the validity of research findings in the game of publication pursuit, which can be exploited for commercial purposes. We have recently seen the emergence of Direct-to-Consumer testing, for the purpose of talent identification and to assess potential for future sports performance, being sold to the unsuspecting public. 'Pay \$100-\$200 and we will tell if you have a future champion on your hands'. There are nearly 40 companies, worldwide, offering analyses of saliva or buccal smear samples without counselling or consideration of the validity of the results or the impact of the report. Many will then offer the opportunity to buy their supplements to enhance training. The consensus agreement (from the researchers who performed the studies 
that these companies quote), is that, at present, DNA testing has no role. SEM physicians need to discourage any parent, child or coach from using these tests (see page 1486).

\section{FROM THE LABORATORY TO THE CLINIC-WHAT ROLE FOR GENOMICS?}

What is the role of 'Omics' in sport? How do we keep up with the essentials? We are practising in the age of personalised SEM; personal whole genome sequencing, personal health records and personal technological health applications (smart phones, etc). The world is getting smaller. This is good for partnerships forcing us to communicate and collaborate-with each other, with the research community and with patients.

There clearly needs to be a willingness to collaborate-to advance not only the science but also the translation to concrete guidelines for clinical SEM practice. New initiatives are required to address these deficiencies in our knowledge, and to develop practical and valid guidance for SEM. Professor Claude Bouchard highlights the danger of performing sports genetics research with limited subject numbers (see page 1492).

Large collaborative studies with appropriately phenotyped subjects, incorporating genome-wide approaches may be able to

\section{Definitions}

Genome: The total DNA of a cell or organism

Polymorphism: Variations in DNA at a specific site

Transcriptomics: The study of the mRNA within a cell or organism

Transcriptome: The total mRNA in a cell or organism

Proteomics: The large-scale study of proteins, including their structure and function, within a cell/system/organism.

Proteome: The set of all expressed proteins in a cell, tissue or organism

Metabolomics: The study of global metabolite profiles in a system (cell, tissue

or organism) under a given set of conditions

Metabolome: The total quantitative collection of low-molecular-weight

compounds (metabolites) present in a cell or organism that participates in metabolic reactions.

Genome Wide Association Studies: Their purpose is to determine alleles that correlate to different diseases and traits with a hypothesis free approach.

deliver some answers. In time, we may understand how to use this information to safely guide athletes. What is clear is that SEM practitioners in the 21 st century need to engage in the genetics of sport, exercise and injury-now.

Twitter Follow Hendrik Dijkstra at @DrPaulDijkstra

Competing interests None declared.

Provenance and peer review Not commissioned; internally peer reviewed.

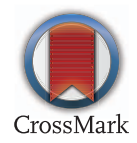

To cite Webborn N, Dijkstra HP. Br J Sports Med 2015;49:1481-1482.

Accepted 8 October 2015

Br J Sports Med 2015;49:1481-1482.

doi:10.1136/bjsports-2015-095643

\section{REFERENCE}

1 Pitsiladis YP, Durussel J, Rabin O. An integrative 'omics' solution to the detection of recombinant human erythropoietin and blood doping. Br J Sports Med 2014;48:856-61. 